\title{
UN REMEDIO CONTRA LA DELINCUENCIA: EL TRABAJO INFANTIL EN LAS INSTITUCIONES DE ENCIERRO DE LA CIUDAD DE MÉXICO DURANTE LA POSREVOLUCIÓN
}

\author{
Susana Sosenski ${ }^{1}$ \\ Centro de Estudios Históricos de El Colegio de México
}

\begin{abstract}
RESUMEN
En la Ciudad de México, durante el periodo posrevolucionario la terapéutica del trabajo se impuso frente a otros tratamientos como forma de prevenir y corregir lo que se consideraba una enfermedad social: la delincuencia infantil. Mientras miles de niños ocuparon los campos de cultivo de las escuelas granjas y las decenas de talleres de las correccionales y escuelas industriales. La mano de obra de los niños de los sectores populares fue utilizada en establecimientos de «protección» a la infancia como retribución a lo que recibían en estos lugares. Bajo la lógica del trabajo como regenerador de un cuerpo y una mente enferma, se pretendió convertir a los niños infractores en los futuros trabajadores y de esa forma incorporarlos al proyecto económico del Estado mexicano.
\end{abstract}

PALABRAS CLAVE: Terapéutica del trabajo. Infancia. Trabajo infantil. Tribunal de menores. Delincuencia.

\section{A REMEDY AGAINST DELINQUENCY: CHILD LABOUR IN LOCK-UP INSTITUTIONS IN POST-REVOLUTIONARY MEXICO CITY}

\begin{abstract}
In post-revolutionary Mexico City, work therapy prevailed over other treatments used to correct what was considered a social disease: child delinquency. Thousands of children took up the fields of farm schools as well as workshops in reformatories and industrial schools. The manual labor carried out by children of the popular sectors was used in childhood establishments as a way to make up for what they received in those places. Based on the logic that work as regenerator of a sick body and an ill mind, the Mexican state tried to turn the young delinquents into the future workers.
\end{abstract}

1 Agradezco la lectura y los inteligentes comentarios de Sebastián Plá, Ana María Carrillo y Cristina Sacristán a una versión preliminar de este texto. 
KEY WORDS: Work therapy. Childhood. Child labor. Juvenile court. Delinquency.

Las acciones tomadas en México en torno al fenómeno de la delincuencia infantil urbana al concluir la Revolución Mexicana (1910-1920) conllevaron a la persecución de amplios contingentes de niños de los sectores populares para los cuales se crearon instituciones de corrección y terapéuticas regeneradoras. En el Tribunal para Menores Infractores creado en 1926 en la Ciudad de México confluyeron miradas médicas, psiquiátricas, pedagógicas, económicas y jurídicas para resolver lo que se consideraba una enfermedad física y moral: la delincuencia infantil. Si bien hubo varias terapéuticas para prevenir y corregir este creciente problema urbano que consistieron en la educación, la gimnasia, los programas de higiene y salubridad, el trabajo se configuró como el eje central para la regeneración de los niños y adolescentes de los sectores populares que caían en poder de la justicia. Es por ello que en este artículo nos concentraremos en analizar la terapéutica del trabajo como correctiva de la delincuencia infantil y mostrar cómo esta terapéutica obedeció a la creación del nuevo tipo de ciudadano que requería el país: productivo, industrializado, trabajador y disciplinado.

No fue fortuito que la búsqueda de ese ciudadano se diera en un contexto de reconstrucción nacional. Aunque entre el viejo y el nuevo régimen hubo continuidades, la posrevolución mexicana se caracterizó por la creación de instituciones, la modernización política, la creciente urbanización y el desarrollo de las fuerzas productivas. Si los sectores populares se habían desbordado y escapado de las manos del gobierno porfirista (1876-1910) provocando una de las revoluciones sociales más importantes del siglo XX; el nuevo régimen —que en parte surgía gracias a ella-, requería establecer un control más eficaz sobre las familias populares y sus hijos. El proyecto de inculcar a los niños de los sectores populares el amor hacia el trabajo para hacer de ellos sujetos productivos continuaría hasta la llegada de Lázaro Cárdenas a la presidencia en 1934. Sin embargo a esta terapéutica cardenista se le agregaría el desarrollo de una conciencia de clase y de organización corporativista.

SigNOS, SÍNTOMAS, DIAGNÓSTICOS

La primera mitad del decenio de 1920 estuvo marcada por insistentes propuestas para separar a los niños de los adultos en las cárceles y juzgados y constituir cortes juveniles para la infancia delincuente que retomaran el mo- 
delo del primer Tribunal para Menores fundado en Chicago en $1899^{2}$. La creación del Tribunal para Menores en el Distrito Federal en 1926 respondió a un movimiento que se extendió por gran parte del mundo occidental para proteger y controlar a la infancia delincuente o en riesgo de llegar a serlo 3 .

Aunque el Tribunal de Menores estaba separado del campo penitenciario, sus instituciones de corrección y de encierro asumieron el modelo penal gene$\mathrm{ral}^{4}$. El Tribunal de Menores partió de la necesidad de saber, de producir diagnósticos y de establecer etiologías. La naciente justicia para menores llamó a escena a las jóvenes protagonistas del cuidado del niño: la pediatría, la psicología infantil y la asistencia social.

Los ayudantes de trabajos sociales y delegados de investigación procedían a levantar el estudio social de los menores infractores en el que se describían las causas determinantes de su ingreso, su biografía y se comenzaba un acercamiento concéntrico al medio familiar, luego al extrafamiliar, reforzado con el testimonio de los acompañantes, familiares o encargados del menor, para concluir finalmente en un diagnóstico a partir del cual se determinaba el riesgo de perversión y grado de culpabilidad del menor. Este estudio proporcionaba, «la materia prima» y la receptividad de la familia a una intervención ${ }^{5}$. Si se consideraba necesario, el estudio se completaba con la reconstrucción de una historia clínica; un cuerpo de médicos y psiquiatras estudiaban el estado actual de salud o de enfermedad del niño, su herencia patológica y discutían su tratamiento ${ }^{6}$. Finalmente se aplicaban exámenes de conocimientos al niño para identificar en qué grado escolar debía ser ubicado y para analizar si tenía retraso escolar, lo cual en la mayoría de los casos se confirmaba.

En los informes médicos, psicológicos y pedagógicos abundaban los antecedentes heredo-alcóholicos, heredo-sifilíticos, heredo-tuberculosos o «neuropsicopatías» de los niños infractores, así como enfermedades y padecimientos físicos ${ }^{7}$. La herencia era «la raíz de todos los males» y una causa potencial

2 Ceniceros, J.A. y Garrido, L. (1936), La delincuencia infantil, México, Botas, p. 23; SANTAMARINA, R. (1923), Observación médico pedagógica de los niños que caen en poder de la justicia, Revista Educación (2), 340-341.

3 AZAola, E. (1990), La institución correccional en México, una mirada extraviada, México, Centro de Investigaciones y Estudios Superiores en Antropología Social, Siglo XXI, p. 52.

4 AzAOLA (1990), p. 67.

5 Donzelot, J. (1990), La policía de las familias, Valencia, Pre-textos, pp. 121, 196.

6 Lima, S.M. (1929), Los niños moralmente abandonados (Tribunal para menores), México, Herrero Hermanos Sucesores, p. 38.

7 En los niños que habían llegado al Tribunal se encontró que el $60 \%$ eran hijos de alcohólicos, el 50\% de sifilíticos, el 30\% hijos de padres con artritis, el 24\% de padres con diver- 
de la delincuencia infantil. Para el decenio de los años treinta se distinguían dos tipos de factores hereditarios: los que podían y los que no podían superarse. Los primeros eran los factores morales, si un hijo de delincuentes era encauzado hacia el camino de la honradez tenía posibilidades de superar su herencia moral. Sin embargo, la herencia física, enfermedades como la sífilis o vicios como el alcoholismo y la drogadicción, eran determinantes para que el niño se convirtiera en un delincuente en el presente o en el futuro. José Ángel Ceniceros y Luis Garrido, prestigiosos profesores y juristas encargados de redactar el Código Penal de 1931, enfatizaron el papel de la herencia biológica en el futuro de los niños y señalaron que el origen de las alteraciones de un menor delincuente se encontraba desde el momento de la concepción e incluso antes ${ }^{8}$. Salvador Lima, profesor jalisciense, combatiente de la revolución y juez fundador del Tribunal de Menores difundía por radio que «la pereza, el vagabundaje y el desprecio al trabajo» tenían por causa «una tara congénita» ${ }^{9}$. El Tribunal de menores, continuaba Lima, «ha estudiado la psicología del niño delincuente y ha llegado a concluir que las turbulencias, los casos de pereza, la apatía y un sinnúmero de defectos, tienen su origen principalmente en las aptitudes transmitidas por herencia» ${ }^{10}$. Sin embargo, el peso del determinismo hereditario comienza a cuestionarse; para el propio Lima, las tendencias hereditarias se podían corregir, debilitar o aniquilar. En su tesis de licenciatura el abogado Francisco Argüelles consideraba que la herencia predisponía al crimen pero ya no la veía como un hecho fatal ${ }^{11}$.

Las miradas especializadas sobre la infancia descubrieron en los niños, muy especialmente entre los de los sectores populares, diversos padecimientos, enfermedades, anormalidades, deficiencias en su desarrollo mental, retraso escolar y tendencia a cometer actos delincuenciales. La delincuencia infantil se vinculó estrechamente con la enfermedad. Manuel Velásquez, director y encargado de un grupo escolar en la Casa de Orientación para Varones, sostuvo en 1932 que al anormal debía considerársele como «un delincuente en germen» ${ }^{12}$.

sas neuropsicopatías y el 18\% de tuberculosos. LiMA (1929), p. 73.

8 CENICEROS y GARRIDO (1936), pp. 77-78.

9 LiMA (1929), p. 23.

10 LiMA (1929), p. 30.

11 ArgüElles, F. (1932), La delincuencia infantil y los Tribunales para menores, México, Universidad Nacional Autónoma de México, Tesis de licenciatura.

12 Velásquez Andrade, M. (1932), La delincuencia juvenil, México, Cultura, p. 49. 
Los psicólogos del Tribunal habían encontrado que sólo el 17 por ciento de los niños infractores eran «normales», el porcentaje restante presentaba diversos grados de deficiencia mental. Se calculaba que en promedio los niños aprehendidos tenían un retardo mental de seis años ${ }^{13}$. Quizá nunca como en estos años la cantidad de niños anormales superó, en los discursos oficales, a los considerados normales. Como señala la antropóloga Elena Azaola, «había, entonces, la presunción de que detrás de la más ínfima violación reglamentaria podía hallarse un sujeto que, por ser 'anormal', 'patológico' en múltiples aspectos, había cometido aquella infracción» ${ }^{14}$. La anormalidad era una herramienta conceptual amplísima en la que se incluían incapacidades físicas, mentales, lingüísticas u orales; abarcaba la destreza motriz y entraban en esta estigmatización los niños sordos, mudos, ciegos, hipertiroideos, glotones, homosexuales, mancos o tuertos.

\section{EL JUICIO}

Las audiencias en el Tribunal de Menores no eran públicas; sólo podían concurrir las personas citadas, familiares, vecinos o patrones ${ }^{15}$. Como se consideraba que el Tribunal era una institución educativa y no punitiva los niños no contaban con defensores de oficio. En tanto se insistía en el espíritu paternal del Tribunal ${ }^{16}$, se esperaba que los niños efectuaran su propia defensa ${ }^{17}$,

13 Dentro de los deficientes mentales había idiotas (edad mental de menos de 2 años); imbéciles (de 7 años) y débiles mentales (menos de 14 años). AZAOLA (1990), pp.57-58; LiMA (1929), pp. 71-74.

14 AzaOla (1990), p. 90.

15 Podemos suponer que en el caso mexicano esta determinación se hizo por las mismas razones que en los casos estadounidense o francés. El primer juez de menores en Chicago (1899) y sus equivalentes franceses explicaban que no debía haber público para evitar la «excitación que producía en los niños el carácter público de su comparición: 'la ausencia de público da excelente resultados, ya que el niño tiende a enorgullecerse del interés que suscita y se vanagloria de ver su nombre en los periódicos'». Era una forma de evitar la emoción popular que podían causar las condenas de niños. DONZELOT (1990), p. 103.

16 Ceniceros y Garrido (1936), p. 39. Este «espíritu paternal», retomado de la justicia estadounidense, era peculiarmente entendido por los empleados del Tribunal ya que llegaban a usar la violencia física (y la tortura) en contra de los menores que se negaban a declarar. Archivo General de la Nación (en adelante AGN), Consejo Tutelar para Menores Infractores (en adelante CTMI), (1928) caja 3, exp. 2418. AZAOLA (1990), p. 50.

17 En el sistema correccional argentino los niños, en cambio, no podían hablar en su propia defensa. GuY, D. (2001), Girls in prison: the role of the Buenos Aires Casa Correccional 
(Ilustración 1) aunque sus testimonios, la mayoría de las veces sólo terminaban constatando su culpabilidad ya que si el acusado negaba su delito se consideraba que era a causa de su carácter simulador y su personalidad voluntariosa. Con todo, las declaraciones de los niños se utilizaban para distinguir indicios de los síntomas, y para establecer diagnósticos y posibles tratamientos.

\section{ILUSTRACIÓN 1. FRENTE A LOS INVESTIGADORES SOCIALES}

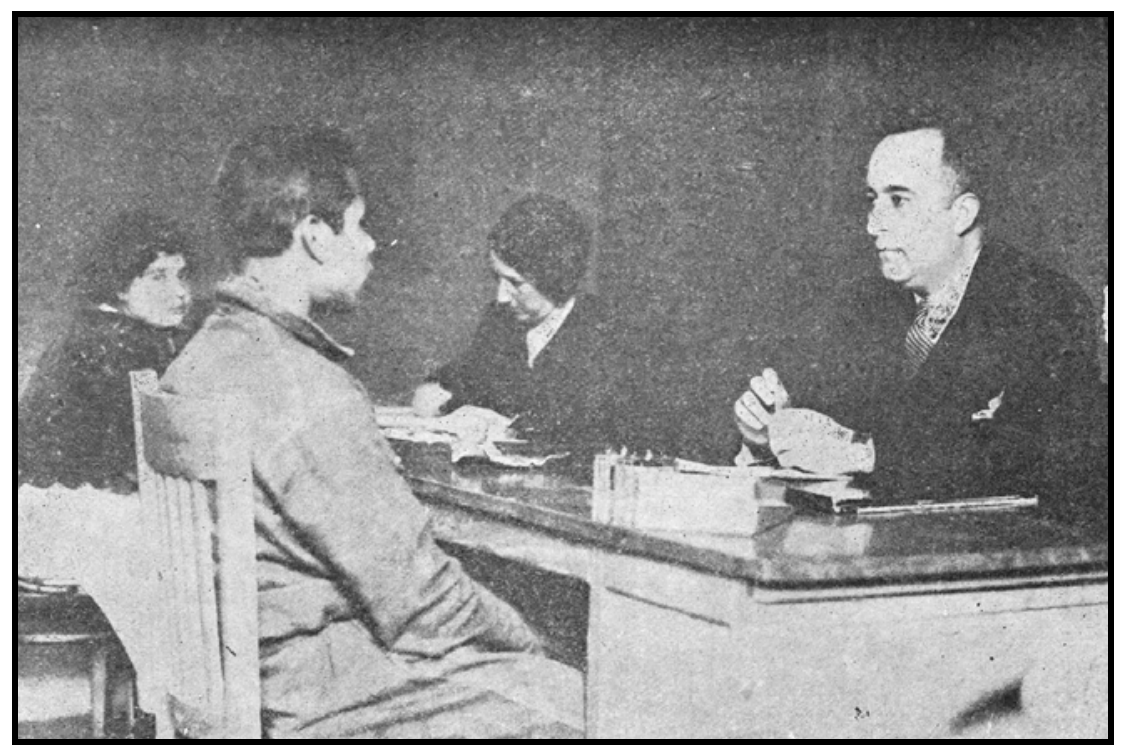

Tomada de CENICERos y GARrido (1936).

Quienes dictaban no la sentencia ni la pena sino la «forma de corrección» eran tres jueces: un juez médico, un juez maestro y un juez abogado, de los cuales uno debía ser obligatoriamente mujer. (Ilustración 2) Al no fijarse una sentencia sino «medidas preventivas o educadoras» ${ }^{18}$, tampoco se establecía el número de años que los niños permanecerían en el encierro lo cual daba

de Mujeres as an institution for child rescue, 1890-1940. En SAlvatore, R.D., AguirRe, C. y JosePH, G.M., Crime and punishment in Latin America: Law and Society since Late Colonial Times, Durham, Duke University Press, pp. 369-390, p. 369.

18 «Reglamento para la calificación de los infractores menores de edad en el Distrito Federal», 19 de agosto de 1926, en CENICEROS y GARRIDO (1936), p. 266. 
como resultado detenciones indeterminadas. Como en el caso español «en la lógica correccional y positivista desaparecía el tratamiento con una duración determinada previamente, porque igual que el médico no sabe lo que tardará en curarse un enfermo, tampoco podía saber el juez el tiempo que duraría la terapia normalizadora ${ }^{19}$. La condena era condicionada a la conducta que mostrara el menor, «el criterio para considerar a un joven curado respondía a cómo se adaptaba a las normas de la correccional» ${ }^{20}$.

\section{ILUSTRACIÓN 2. UN MENOR INFRACTOR FRENTE A LA JUEZ}

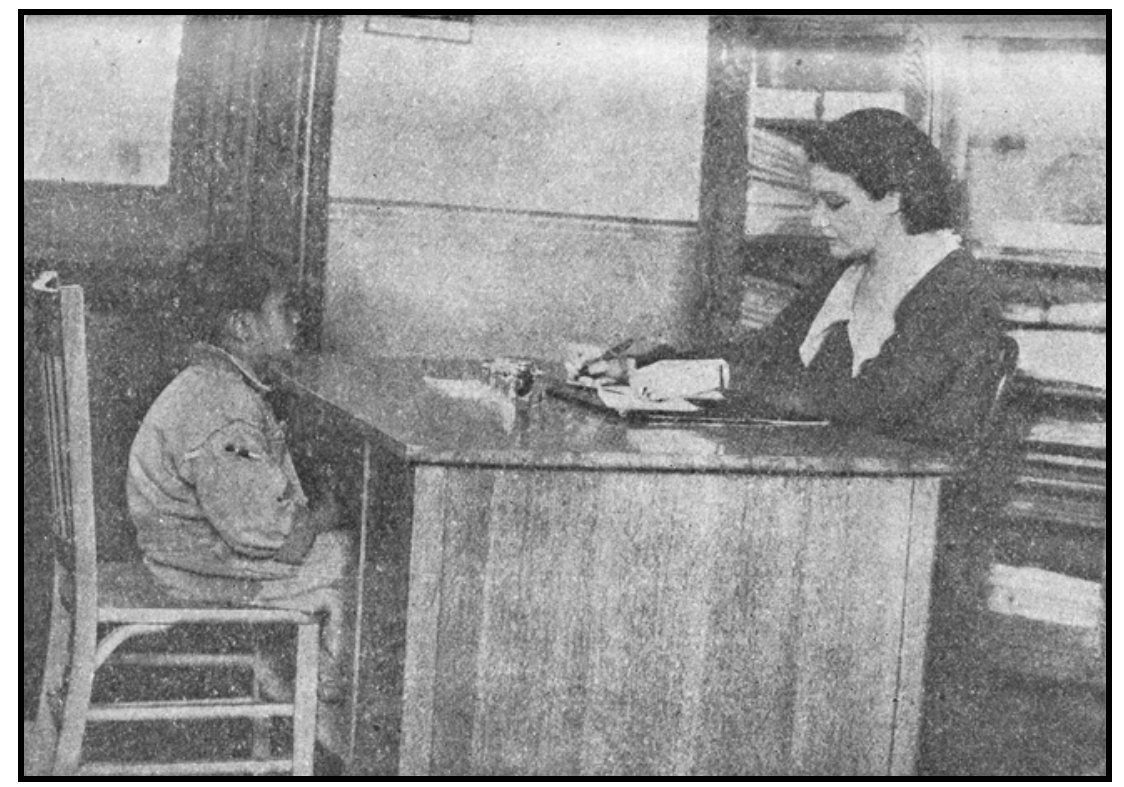

Tomado de CENICEROS y GARRIDO (1936).

Las resoluciones del Tribunal podían ir en varios sentidos, siempre cuidando que sirvieran para «el restablecimiento normal» del niño en la sociedad

19 FERnÁndez, P.T. (1996), La infancia delincuente y abandonada. En BorRÁs Llop, J.M., Historia de la infancia en la España contemporánea, 1834-1936, Madrid, Ministerio de Trabajo y Asuntos Sociales/Fundación Germán Sánchez Ruipérez, pp. 461-521, p. 496.

20 FERNÁNDEZ (1996), p. 496. 
y «su acción futura de ciudadano útil»» ${ }^{21}$ La mayor parte de los menores eran liberados y enviados a su hogar (Tabla I). Un segundo grupo debía ser sustraído del ambiente de «contagio» en el que vivía, para lo que se internaba a los niños en instituciones de corrección: casas de orientación, escuelas de la beneficencia, escuelas granjas, hospicios, casas del niño o escuelas industriales. En menor grado los niños eran enviados a las escuelas primarias o destinados a servir en casas particulares.

\section{TABLA I}

\begin{tabular}{|lrr|}
\hline \multicolumn{1}{|c|}{$\begin{array}{c}\text { Resoluciones dictadas } \\
\text { en el Tribunal de Menores } \\
\text { entre 1927-1931 }\end{array}$} & $\begin{array}{r}\text { Número } \\
\text { de niños }\end{array}$ & \% \\
Libres & 2.565 & 56.0 \\
A instituciones de corrección & 1.546 & 33.8 \\
Prófugos & 241 & 5.3 \\
Reclusión escolar & 130 & 2.8 \\
Como adoptados en casas particulares & 93 & 2.0 \\
Quedan en el Tribunal esperando un lugar en & 1 & 0.0 \\
los establecimientos & 1 & 0.0 \\
Falleció & & \\
Total & $\mathbf{4 . 5 7 8}$ & $\mathbf{1 0 0}$ \\
\hline
\end{tabular}

Elaborada a partir de los datos de Roberto Solís Quiroga en CENICEROS y GARRIDO (1936).

Si la delincuencia infantil era vista como una enfermedad y más tarde hasta como una epidemia, resulta lógico que el pensamiento unánime de los protectores de la infancia fuera el de «prevenir antes que curar.» Esta idea no era privativa de la institución correccional; la política preventiva posrevolucionaria distinguió a los individuos a partir no sólo de sus actos delictivos sino de sus «predisposiciones», creando «sospechosos» y criminalizando a los sectores populares ${ }^{22}$. Sin embargo, la prevención de la delincuencia infantil, si bien se apoyaba en las políticas de escolarización obligatoria y en algunos casos en

21 LIMA (1929), p. 34.

22 Véase Piccato, P. (2001), City of Suspects. Crime in México City, 1900-1931, Dirham, Londres, Duke University Press. 
la colocación de los niños como aprendices en talleres artesanales o como domésticos en las casas particulares se quedaba generalmente como discurso o se intentaba aplicar a los niños que por algún motivo ya habían delinquido. La prevención de la delincuencia infantil provocó la estigmatización de los niños de los sectores populares. Antes de comprobar si efectivamente estos menores habían quebrantado una regla o disposición, ya eran etiquetados con «tendencias» al robo, a la criminalidad, al vicio, a la vagancia, a la homosexualidad o al alcoholismo. Todo niño o adolescente que llegaba al Tribunal era desde el principio un sospechoso, un delincuente en potencia. Con esta idea de la prevención y del «predelincuente» el Tribunal justificaba su intervención, sin importar que «no hubiera un delito, lo habría tarde o temprano» ${ }^{23}$.

\section{TERAPÉUTICA DEL TRABAJO}

Durante la posrevolución se ejecutó la lógica del trabajo como una terapéutica contra las enfermedades mentales ${ }^{24}$ y contra lo que se consideraba una suerte de «enfermedades sociales» infantiles: la delincuencia, la vagancia y la mendicidad. El niño delincuente era un enfermo moral y mental al que había que formar y sanar, para lo cual se requerían diversos tratamientos, profilácticos, psiquiátricos, higiénicos, gimnásticos y laborales. En el discurso oficial las actividades laborales infantiles dentro de las instituciones correccionales posibilitaban que los menores obtuvieran recursos pecuniarios con la venta de sus productos, desarrollaran aptitudes técnicas, adquirieran los valores intrínsecos al trabajo: disciplina, puntualidad, productividad y, «el amor por el trabajo material que tanto dignifica al hombre» ${ }^{25}$.

El trabajo como tratamiento dentro de los sistemas disciplinarios fue un fenómeno que apareció en el siglo XIX en varios países. En las sociedades del Antiguo Régimen no se hablaba de terapéuticas o tratamientos para curar la delincuencia sino de castigos, mazmorras y torturas para sancionarla. El siglo XIX trajo consigo la idea de que la regeneración y la rehabilitación del delincuente se darían a través del trabajo. Si bien durante el Antiguo Régimen hubo una condena religiosa y moral a la ociosidad, el siglo XIX valoró como

23 AzaOla (1990), pp. 62 y 63.

24 Véase SACRISTÁn, C. (2005), Por el bien de la economía nacional. Trabajo terapéutico y asistencia pública en el Manicomio de La Castañeda de la ciudad de México, 1929-1932, Manguinhos, 12 (3), 675-692.

25 El Universal, 24 de febrero de 1924, p. 4. 
nunca el trabajo, consecuencia en parte de la «tentativa de generalización de la moral burguesa mediante el desarrollo del hábito del ahorro y de la adquisición ${ }^{26}$. Jacques Donzelot encuentra que a comienzos del siglo XIX el internamiento de los delincuentes presentaba una estructura específica: «el espacio cerrado; una forma privilegiada de tratamiento: el trabajo; una misma función esencial: la moralización $»^{27}$. El trabajo corporal fortificaba y vigorizaba el cuerpo y el espíritu, permitía alcanzar una vida modesta, austera y ordenada ${ }^{28}$.

Durante el siglo XIX los presos eran considerados enfermos de alma y de cuerpo, criaturas inferiores, defectos en la escala de evolución humana; por ello debían ser tratados a través del trabajo, «mediante él se les mostraría que el cuerpo y el alma enfermos podían ser sometidos al proceso de regeneración, condición ineludible para reincorporarse a la sociedad» ${ }^{29}$. El trabajo en las cárceles se concibió como una forma de regeneración pero también como una ayuda para financiar a las instituciones con los productos que se manufacturaban dentro de ellas.

No existen estudios que nos permitan conocer la utilización del trabajo como terapéutica para la delincuencia infantil durante el porfiriato pero sabemos que en ocasiones se aplicó como castigo a los menores infractores: en la Escuela Correccional para Mujeres ubicada en el pueblo de Coyoacán se mantenía a las menores en la reclusión «mediante una severa disciplina carcelaria, considerando el trabajo como una parte del castigo y no como una terapéutica del espíritu ni como una capacitación para la vida» ${ }^{30}$.

Si durante el siglo XIX todavía se encontraban instituciones de encierro donde el trabajo se utilizaba como castigo, en las primeras décadas del siglo $\mathrm{XX}$ se insistió en que el trabajo debía emplearse como una forma de regenerar a los delincuentes. Numerosos artículos para regir el trabajo en las instituciones penitenciarias y correccionales se promulgaron en leyes, reglamentos y códigos. El artículo 18 de la Constitución Política de los Estados Unidos Mexicanos de 1917, emanada del proceso revolucionario, señaló que los Gobiernos de la Federación y de los Estados debían organizar el sistema penal

26 DonZelot, J. (1991), Espacio cerrado, trabajo y moralización. En CASTEL, R., Espacios de poder, Madrid, La Piqueta, pp. 27-51, p. 37.

27 DONZELOT (1991), p. 38.

28 Padilla Arroyo, A. (2001), De Belem a Lecumberri: pensamiento social y penal en el México decimonónico, México, Archivo General de la Nación, p. 295.

29 Padilla Arroyo (2001), p. 298.

30 De hecho, el edificio semejaba a una cárcel y estaba resguardado por soldados. MARín HERNÁNDEZ, G. (1991), Historia de las instituciones de tratamiento para menores infractores del Distrito Federal, México, Comisión Nacional de Derechos Humanos, pp. 36-37. 
sobre la base del trabajo como medio de regeneración. El Reglamento para la calificación de los Infractores Menores de Edad en el Distrito Federal de 1926 indicó que una de las funciones de la Casa de Observación (lugar donde permanecían los niños mientras eran estudiados), era «crear hábitos de orden, de trabajo, de veracidad, de servicio, de estudio, de aseo» (Art. 73) ${ }^{31}$. El Código Penal de 1929 señaló que la reclusión en un establecimiento de educación correccional se haría «efectiva en una escuela destinada exclusivamente para la corrección de delincuentes menores de dieciséis años, con aislamiento nocturno y aprendizaje industrial o agrícola durante el día, con fines de educación física, intelectual, moral y estética» (Art. 122) ${ }^{32}$. El Código de Procedimientos Penales para el Distrito y Territorios Federales de 1931 prescribió que durante el tiempo de su reclusión, los menores estarían obligados a trabajar de acuerdo con sus facultades (Art. 402). ${ }^{33}$ En conclusión, durante la posrevolución el trabajo fue obligatorio en las prisiones e instituciones correccionales porque era la «base de la regeneración de los reclusos». Es interesante observar esta insistencia en el uso del término «regeneración» ya que revela el aparato conceptual proveniente de la biología y la medicina que se colaba en el tratamiento de los menores infractores. La regeneración de los menores, al igual que la del cuerpo o la de las plantas, significaba renovación, crecimiento de nuevos tejidos, órganos y valores que reemplazarían aquellos perdidos o dañados por heridas, por la degeneración moral o física.

El andamiaje legislativo dejaba muy claro que la política estatal hacia la delincuencia infantil y adulta tendría como uno de sus ejes centrales la regeneración y la rehabilitación a través del trabajo que, junto con la educación, la gimnasia, la higiene y, en algunos casos, el tratamiento psiquiátrico ${ }^{34}$ formarían el corpus para alejar a los pequeños delincuentes del ocio y la improductividad.

A finales de los años veinte se habían hecho estudios especiales de las condiciones de los establecimientos correccionales para niños y niñas y se había formulado

31 CEniceros y GARrido (1936), p. 278.

32 Ceniceros y Garrido (1936), p. 250.

33 Ceniceros y GARRido (1936), p. 285. El subrayado es mío.

34 «El trabajo y la asistencia a la escuela son procedimientos aplicables a todos los delincuentes [mientras que...] el tratamiento médico, en cambio, requiere previamente el estudio y selección de los reos que necesiten de él». RODRÍGUEZ CABO, M. (1935), El tratamiento médico de los delincuentes, ponencia presentada en el CONGRESO NACIONAL PENITENCIARIO, Memoria del primer Congreso Nacional Penitenciario celebrado en la ciudad de México, del 24 de noviembre al 3 de diciembre de 1932, convocado por la Dirección Antialcohólica, México, Talleres Gráficos de la Nación, pp. 110-111. 
«un programa completo para cambiar completamente la orientación del primero de ellos, con la mira de que los corrigendos realicen las actividades que les permitan reformarse y prepararse para ganar después la vida convenientemente. En particular se ha tenido en cuenta la organización de los talleres y las relaciones estrechas que deben existir entre estos y la escuela propiamente dicha ${ }^{35}$.

En la escuela correccional para mujeres se abrieron talleres de hilados y tejidos, pastas alimenticias, juguetes de trapo, costura, paraguas, sombrillas, bolsas de piel, guantes, mantelería, ropaje, sarapes y encurtidos.

De tal forma escuelas-granjas, escuelas industriales, casas correccionales y todos aquéllos establecimientos que recibieron a menores infractores para su «readaptación»se organizaron bajo la premisa de que en su interior los niños debían no sólo aprender un oficio sino también a trabajar y a producir. Los talleres y el aprendizaje de oficios parecieron convertirse en el centro del programa de regeneración de los menores. En la Casa de Orientación para mujeres se señalaba que «del aprendizaje de un oficio útil y práctico depende que la menor, una vez puesta en libertad, posea los medios para bastarse a sí misma sin recurrir a actos ilícitos como la prostitución o el robo. El trabajo obra eficazmente en las menores delincuentes, no sólo desde el punto de vista material sino que sus repercusiones en el campo espiritual son definitivas» ${ }^{36}$.

La laborterapia, laboroterapia o terapia del trabajo fue también un recurso de las instituciones psiquiátricas decimonónicas retomado por las instituciones correccionales posrevolucionarias ${ }^{37}$. Además de contribuir al mejoramiento de la salud moral, la laboroterapia funcionó como una terapéutica para recuperar la salud mental. Aunque a veces no quedara muy clara la forma en que operaría a nivel psíquico, los funcionarios del Tribunal recetaban la terapia laboral para todo tipo de casos. Alejandro, de ocho años, quien había herido a uno de sus hermanos y asesinando al otro con una carabina, recibió como tratamiento, para «evitarle ratos amargos» y «borrar la penosa impre-

35 Informe de la Dirección de Acción Cívica, El Niño, Agosto, 1929, p. 53.

36 MARÍN HERNÁNDEZ (1991), p. 40.

37 Ver SACRISTÁN (2005); BARRIOS FLORES, L.F. (2002), El internamiento psiquiátrico en España: de Valencia a Zaragoza (1409-1808), Revista Cubana De Salud Pública, 28 (2), 224-245. En el pabellón infantil del Manicomio general de México (La Castañeda) había campos para trabajos de hortaliza, salones con equipo para manufacturar tapetes, realizar costuras y elaborar algunos artículos de juguetería, luego se instaló un taller de carpintería. Olguín Alvarado, P. y VilledA, R.T. (2003), Escuela para niños anormales, anexa al Pabellón de Psiquiatría Infantil del Manicomio General, 1930-1940. En Cuadernos Para la historia de la salud, México, Secretaría de Salud, pp. 89-99, pp. 18-25, 89, 97, 98. 
sión que este inusitado accidente ha causado en el lugar», la internación en un establecimiento «donde aprendiera un oficio y en general se educara» ${ }^{38}$. En este caso la terapia del trabajo parecería tener una función de distracción. El miedo de las autoridades a una adolescencia rebelde, poco ajustada a los cánones sociales y a los roles de género, veía al trabajo como una técnica para disciplinar esa rebeldía, para someter la insubordinación de los adolescentes a las normas sociales establecidas, pongo por caso el de una adolescente activa sexualmente a quien su padre acusó de estar «violada» y solicitó su ingreso al Tribunal para «su corrección». Ahí se ratificó que era una muchacha «frívola» a quien le gustaba «hacerse notar por los muchachos cuando va al comedor». En suma, requería una «oportuna intervención» que consistía en «someterla a un reglamento de trabajo regular que ocupe su mente en problemas nuevos y que formen en ella hábitos de vida activa y honrada» ${ }^{39}$.

\section{FABRICAR MANUFACTURAS}

El control de la infancia y la adolescencia fue sólo uno de los objetivos de la terapia del trabajo. Miles de menores se encontraban en instituciones de beneficencia, escuelas granjas, escuelas industriales, casas correccionales y en el propio Tribunal con lo cual representaban una erogación presupuestal significativa para el Estado. No deben exagerarse las utilidades económicas logradas por el empleo de mano de obra infantil dentro de las correccionales pero tampoco puede obviarse que estos establecimientos eran también unidades productivas que utilizaban el trabajo infantil bajo el supuesto de que los niños debían retribuir la educación, techo, comida y ropa que las instituciones les proporcionaban. En 1924 en una de las recién creadas Escuelas Granjas del Niño se hizo hincapié en que los niños desamparados podrían aprender a trabajar en labores agrícolas «para que ellos mismos se ganen su subsistencia y crezcan hombres útiles a la sociedad». Además se preveía que la institución podría sostenerse con el trabajo de sus alumnos y con el de seis niñas que serían las encargadas «de las atenciones domésticas propias a su educación para servir a sus compañeros $»^{40}$. La terapia del trabajo tuvo entonces otro propósito económico: generar ganancias para las instituciones.

38 AGN, CTMI, (1929) caja 6, exp. 3436.

39 AGN, CTMI, (1927) caja 1, exp. 853.

40 El Universal, 2 de marzo de 1924, p. 6. 
Los niños enviados desde el Tribunal a diversas instituciones trabajaban tanto que a fines de 1922 los alumnos de la Escuela Correccional para Varones produjeron dos toneladas y media de jabón mensuales suficientes «para satisfacer las necesidades de todas las dependencias de Gobierno» ${ }^{41}$. En la Escuela Francisco I. Madero los alumnos elaboraban pan con el que se suplían las necesidades de la cárcel municipal ${ }^{42}$. En la Escuela Correccional para Mujeres las niñas se dedicaban largas horas al cultivo del gusano de seda ${ }^{43}$.

Aunque el artículo 123 de la Constitución Política prohibía la contratación de menores de 12 años, la Beneficencia Pública sufragaba buena parte de sus gastos gracias al trabajo infantil. En la Casa del Niño, que atendía a más de mil menores entre 7 y 12 años, los alumnos debían entregar el $25 \%$ de sus ganancias a la Beneficencia «para rembolsar, en parte los gastos de sostenimiento ${ }^{44}$. Los niños fabricaron tanta ropa, calcetines, medias de hilo y lana, suéteres, manteles, colchas y toallas que en 132 días del año 1934 con la venta de esas manufacturas se obtuvieron 72000 pesos. En la Escuela Industrial, cuyo objetivo era procurar en los alumnos una «educación productora», no cabía duda de que lo lograban ya que junto a algunos ex alumnos contratados como obreros, los adolescentes inscritos producían millares de juguetes y entre 10.000 y 12.000 piezas diarias de pan con el que se surtía a 7 establecimientos y a 4 comedores públicos de la beneficencia ${ }^{45}$.

\section{FABRICAR PRODUCTORES}

En sus estudios sobre la prisión Michel Foucault señaló que el trabajo se concibió como un acompañamiento de la vida en el encierro y como un agente de la transformación penitenciaria, que tendió fundamentalmente a convertir a las prisiones en fábricas, no tanto de manufacturas sino de individuos-máquina:

41 GOBIERNO DEL DISTRITO FEDERAL (1923), p. 61.

42 González Navarro, M. (1985), La pobreza en México, México, El Colegio de México, p. 235.

43 GOBIERNO DEL DISTRITO FEDERAL (1923), p. 61.

44 El saldo se dividía luego en dos partes «una que se entrega en efectivo a los alumnos y otra que se deposita en las cuentas de ahorros que cada uno tiene en el Monte de Piedad». En 1932 había 1251 escolares, en 1933 subió a 1494 y en 1934 ya eran 1 567. JUNTA DIRECTIVA DE LA BENEFICENCIA PÚBLICA EN EL DISTRITO FEDERAL (1934), Memoria de la labor realizada de septiembre de 1932 a agosto de 1934, México, Cultura, pp. 184,188.

45 JUNTA DIRECTIVA DE LA BENEFICENCIA PÚBLICA EN EL DISTRITO FEDERAL (1934), p. 193. 
El trabajo de la prisión debe ser concebido como si fuera de por sí una maquinaria que transforma al penado violento, agitado, irreflexivo, en una pieza que desempeña su papel con una regularidad perfecta. La prisión no es un taller; es -es preciso que sea en sí misma - una máquina de la que los detenidos-obreros son a la vez los engranajes y los productos. [...] Si, a fin de cuentas, el trabajo de la prisión tiene un efecto económico, es al producir unos individuos mecanizados según las normas generales de una sociedad industrial ${ }^{46}$.

Foucault insistió que lo relevante del trabajo penal eran los efectos que ejercía sobre los individuos: «es un principio de orden y de regularidad; por las exigencias que le son propias, acarrea de manera insensible las formas de un poder riguroso; pliega los cuerpos a unos movimientos regulares, excluye la agitación y la distracción, impone una jerarquía y una vigilancia», pretende reproducir «un microcosmo de una sociedad perfecta» ${ }^{47}$. Después, autores como Darío Melossi y Máximo Pavarini apuntaron que el trabajo penitenciario buscaba también «la creación de 'sujetos virtuales', tal como son necesarios para el mercado de libre competencia, que a la producción, económicamente ventajosa, de mercancías» ${ }^{48}$. En el caso mexicano encontramos que el trabajo en el encierro durante la posrevolución, conllevaba una función ideológica, económica y productiva, además de la formación de ciudadanos útiles para el desarrollo del proyecto estatal modernizador.

Entre 1921 y 1934 el país transitó entre una muy incipiente industrialización, la consolidación de un sistema político y de un proyecto social de corte capitalista ${ }^{49}$. Si bien es cierto que los gobiernos posrevolucionarios mostraron su preocupación por la infancia mexicana, a la que consideraban el embrión de los futuros ciudadanos, concentraron su atención en la infancia de las clases populares ya que en ésta se veía al obrero del porvenir que habría de colaborar en la prosperidad económica de la nación. Si el ciudadano revolucionario debía ser higiénico, ahorrador, disciplinado, consumista y trabajador, el obrero debía sumar a estos valores el ser industrioso, calificado, productivo, capacitado, amante del trabajo, defensor de la organización sindical y colectiva. Y, si los adultos se formaban desde pequeños, las instituciones para la infancia debían encargarse de

46 Foucault, M. (1984), Vigilar y Castigar, nacimiento de la prisión, México, Siglo XXI, p. 245.

47 Foucault (1984), p. 240.

48 Melossi, D. y PaVArini, M. (1980), Cárcel y fábrica. Los orígenes del sistema penitenciario (siglos CVI-XIX), México, Editorial Siglo XXI, p. 174.

49 PEÑA, S. (1996), Trabajadores y sociedad en el siglo XX, $4^{\mathrm{a}}$ ed., México, Siglo XXI, pp. 61-85. 
introducir estos valores a los niños. Así el modelo educativo - en el que se retomaron los principios de la escuela de la acción y la educación para el trabajo- y el correccional se subordinaron al paradigma capitalista en el que la corrección de la delincuencia se ajustó a la política económica.

El trabajo creaba «hábitos de laboriosidad y constancia», promovía la disciplina, hacía que los menores lograran identificarse con un grupo social, los acostumbraba a ciertos horarios y a ciertas rutinas. La disciplina del trabajo dentro de las instituciones correccionales se erigía como un agente transformador de las personalidades violentas, irreflexivas y voluntariosas. Frente a estos sujetos reales detenidos se construía una imagen de un sujeto-niño ideal disciplinado, obediente y productivo. En tanto el niño era una sustancia maleable se conservaba una esperanza de poder transformarlo con la terapéutica adecuada. Las correccionales del México posrevolucionario, tal como lo advirtió Foucault respecto de las instituciones penitenciarias francesas, también eran modelos sociales y de organización que pretendían transformar a los niños en sujetos disciplinados y adiestrados para el trabajo en las fábricas, objetivo necesario para cristalizar el proyecto industrializador del país.

El discurso de formar individuos útiles a la economía nacional no estuvo oculto. La Escuela Centro Industrial Rafael Dondé de la Beneficencia Privada fundada en 1931 recibió a muchos chicos provenientes del Tribunal de Menores. Ahí se les proporcionaba una educación semi militarizada y se les preparaba para ser «ciudadanos útiles, disciplinados y trabajadores», con «hábitos de trabajo, limpieza, justicia, equidad y amor a la patria ${ }^{50}$. Los 400 alumnos aprendían diversos oficios pues una de las finalidades del establecimiento era funcionar simultáneamente «como escuela y como fábrica», por ello se debían formar «obreros técnicos aptos para luchar ventajosamente en el medio en el cual cada uno actuaría después de salir de la escuela (...) los talleres dieran el rendimiento económico necesario, capaz de cubrir las erogaciones que la enseñanza impone» ${ }^{51}$. Esta política de escuela-taller predominó en una gran parte de los establecimientos educativos del período. En las escuelas correccionales los niños debían trabajar desde el momento en que ingresaban; los más pequeños eran dedicados al cultivo de los jardines y de la hortaliza, a la cría de aves de corral y conejos y al cuidado del apiario.

La inserción temprana de los niños en el mundo de trabajo urbano, la oferta de un maestro artesano para recibir a un niño infractor en su taller como

50 MARÍn HeRnÁNDEZ (1991), p. 27.

51 Cincuenta años al servicio de México. Escuela Secundaria Técnica no. 5. Rafael Dondé. Primera década de vida institucional, 1930-1940. (Mecanografiado) s.p.i. 
aprendiz, la promesa de los padres de colocar a sus hijos en talleres o el servicio doméstico en casas de la ciudad eran argumentos válidos para conceder la libertad a los menores aprehendidos en el Tribunal. El trabajo, más que la escuela, sería el factor que alejaría a los niños pobres de la vida ociosa, la vagancia y la holgazanería. Para liberar a un niño, al igual que en el caso español, se tomaba en cuenta

«su actitud frente al trabajo; si aprendía con rapidez y entusiasmo un oficio y se adaptaba a las regularidades de la institución. La muestra más evidente de curación-normalización era asumir los valores morales de los educadores y el sometimiento a la disciplina del trabajo, ejemplo de que podría convertirse en un honrado trabajador cuando le pusieran en libertad $»^{52}$.

La política social de los gobiernos emanados de la revolución mexicana con respecto a la infancia de los sectores populares fue claramente clasista y estuvo permeada por un determinismo social. Para los niños de las clases populares había escasas posibilidades de ascenso social y los funcionarios del gobierno se encargaron de reducir todavía más esas posibilidades. Aquellos niños que pudieron ir a las atiborradas escuelas de la gran urbe, recibieron también una educación para el aprendizaje de oficios y la producción. Estas acciones reflejaban no sólo una política clasista sino también que el trabajo infantil no tenía una valoración negativa, lo cual muestra que este es un concepto cultural que varía en el tiempo y en el espacio histórico.

Los archivos del Tribunal de menores registran alrededor de un $26 \%$ de reincidencias lo cual podría hacer pensar que la terapéutica del trabajo era exitosa. Sin embargo en muchos casos el trabajo como terapéutica no tuvo el éxito esperado y pareció una suerte de tratamiento placebo. Un caso ilustrativo es el de Pedro, cuando sus padres intentaron sacarlo del Tribunal enumerando sus virtudes, los funcionarios aseguraron que sus opiniones no podían ser tomadas en serio porque sólo reflejaban «el interés que tienen por lo que produce el trabajo de Pedro» y por lo que obtenían por «el fruto de su trabajo». Paradójicamente, luego de esta aseveración, le otorgaron la libertad cuando su madre comprobó haberle conseguido trabajo en un taller mecánico. Este empleo poco modificó su conducta. Un mes después el chico regresó a la correccional por el robo de una bolsa de mano y de artículos en un puesto de ropa. Al cumplir los 14 años en su expediente se apuntó que había alcanzado el grado de oficial zapatero y ayudante de electricista además de haber aho-

52 FERNÁNDEZ (1996), p. 496. 
rrado 50 pesos en efectivo fruto de su trabajo dentro de la correccional. Otra vez en libertad, robó una franela y lesionó a un hombre con una navaja «gillette.» Los siguientes cinco años fueron de reinternamientos y fugas ${ }^{53}$.

Los funcionarios del Tribunal indicaban a los padres que sólo dejarían libres a sus hijos con la condición de que concurrieran a la escuela y trabajaran en algún lugar fijo. En general, lo segundo se cumplía más fácilmente que lo primero; las escuelas estaban llenas e implicaban gastos que muchas veces las familias no podían sufragar ${ }^{54}$. Pronto los padres aprendieron a utilizar «desde abajo» el discurso del trabajo para responder al Tribunal en los términos que los funcionarios deseaban escuchar. Para ello conseguían cartas que aseguraban el ingreso de sus hijos a talleres artesanales, hacían promesas de colocarlos en algún taller, proponían llevarlos a trabajar a la fábrica con ellos o ubicarlos como sirvientes domésticos. El padre de Modesto, un adolescente que ayudaba a su familia con la venta de chicles en la plaza de la Constitución (zócalo), intentó retirar a su hijo del Tribunal de Menores al que él mismo había llevado con la velada intención de que fuera inscrito en la Escuela Industrial. Logró que dejaran en libertad a su hijo cuando «ofreció que si lo dejaban salir» lo inscribiría en una escuela primaria y en un taller de carpintería ${ }^{55}$.

Muchas familias presentaban cartas de maestros artesanos que prometían trabajo a los menores cuando salieran del Tribunal. Andrés, de 15 años, vendedor de billetes de lotería y de periódicos, luego de una fuga y un par de reingresos a la correccional consiguió su liberación cuando su madre obtuvo una carta de un maestro mecánico en la que se comprometía a proporcionar trabajo al menor en el taller que estaba a su cargo ${ }^{56}$. Cuando el niño Federico fue aprehendido «por pederastia» (sic) en mayo de 1929, sus familiares lograron que el maestro tapicero Luis Carrillo escribiera una carta en la que hacía constar que estaba «en la mejor disposición» de tomar a su cargo «para su aprendizaje a pedimento de su mamá la Sra (...) a un hijo suyo de nombre Federico. Comprometiéndome a velar por su educación y aprendizaje.» Luego de la visita de los delegados de protección y vigilancia el tapicero

53 AGN, CTMI, (1928) caja, 5, exp. 3116.

54 Aunque la educación estatal era gratuita, las familias populares no lograban cubrir los cuantiosos gastos que representaba la asistencia de sus hijos a la escuela: excursiones, ropa, materiales, libros, útiles.

55 AGN, CTMI, (1928) caja 4, exp. 2637. El subrayado es mío. Casos como este hay muchos otros, ver por ejemplo AGN, CTMI, (1928) caja 3, exp. 2427.

56 AGN, CTMI, (1927) caja 1, exp. 62. Casos similares en: AGN, CTMI, (1927) caja 1, exp. 1242; AGN, CTMI, (1928) caja 3, exp. 2194; AGN, CTMI, (1932) caja 15, exp. 5324. 
ratificó que se haría cargo del menor dándole alojamiento, alimentos, ropa limpia, etc. Respecto al sueldo me dijo que no podía asignarle determinada cuota diaria por de pronto, pero que vería de lo que es capaz el niño, para darle una cantidad fija. El Sr. Carrillo promete además, enviar al menor a la Escuela Nocturna, lo cual no sería posible este año por estar los cursos muy avanzados. El Sr. Carrillo ofreció traer cartas de recomendación en que conste que es persona de fiar por su formalidad y buena conducta. Por la conversación tenida con él pude apreciar su moralidad y buenas intenciones respecto a Federico ${ }^{57}$.

Sin embargo, la terapia del trabajo como rehabilitadora tenía sus problemas. Aunque días después de recibir al menor el artesano manifestó que estaba contento con él y que le compraría ropa y zapatos «pues está muy mal vestido y carece en absoluto de calzado», en la última visita de los funcionarios encontraron cerrado el taller. El artesano había muerto y la familia del menor se había mudado de domicilio.

Los niños también se apropiaban del discurso y los valores del trabajo como regenerador o, al menos, lo utilizaban a su favor. Al pedir su libertad el adolescente Amado señalaba en una carta con excelente caligrafía que ya podía ganarse «la vida honradamente, ya que sé trabajar». Aseguraba querer salir «con la frente levantada y poder buscar trabajo». En otra carta revelaba haber asumido todos los valores inculcados en la correccional y que una persona «muy buena» lo ayudaría cuando estuviera fuera de la correccional para ir «por el camino del bien y por él tendré trabajo, casa y ganaré dinero para gastar en lo que necesite y ahorrar para que con los ahorros primero Dios haga yo algún negocio y hacerle bien a la humanidad ya que no es más que en lo que pienso» 58 .

\section{FABRICAR SERVIDUMBRE}

La salud del cuerpo y de la mente podía lograrse entonces en lugares de aislamiento como correccionales y escuelas pero también en espacios exteriores como los talleres y fábricas. Otro espacio considerado como educador, regenerador y corrector era el servicio doméstico por ser una actividad laboral infantil con «autoridad y disciplina». Sin embargo, por ser un ámbito en de mujeres pobres, generalmente solas y jóvenes, con frecuencia las élites y funcionarios gubernamentales ligaron el trabajo doméstico con la prostitución.

57 AGN, CTMI, (1928) caja 4, exp. 2864.

58 AGN, CTMI, (1930) caja 7, exp. 3577. 
En ese sentido, resulta tan interesante como contradictorio que los funcionarios del Tribunal para Menores encontraran una salida al problema de las niñas delincuentes colocándolas en casas particulares. Al igual que en el siglo XIX, después de la Revolución Mexicana, una de las grandes revoluciones sociales del siglo $\mathrm{XX}$, la casa privada continuaba considerándose el espacio femenino por antonomasia.

A las niñas detenidas en las casas de observación del Tribunal se las adiestraba y entrenaba para trabajar en labores domésticas y se las criticaba duramente si no se las encontraba afectas a ellos. No olvidemos que las categorías de género cruzaban las ideas penitenciarias: las niñas debían realizar trabajos «propios de su sexo» ${ }^{59}$, tener «predilección por los quehaceres domésticos» ${ }^{60}$, ser diestras en trabajos agrícolas (floricultura, arboricultura, hortaliza) y saber criar animales ${ }^{61}$.

La Ley de Relaciones Familiares de 1917 producto de la Revolución Mexicana, señaló que los niños adoptados tendrían los mismos derechos que los hijos por nacimiento, lo cual limitó la adopción con fines de servidumbre. El Código Civil de 1928 fortaleció la definición de adopción como la formación familiar ${ }^{62}$. Sin embargo, la legislación no logró erradicar definitivamente la tradicional práctica de adoptar niñas para dedicarlas al servicio doméstico. El Código Penal de 1929 permitía que el menor delincuente moralmente abandonado fuera confiado en situación de libertad vigilada, a una familia honrada (Art. 183) ${ }^{63}$. El Código Penal de 1931 refrendó esta práctica: si el niño se encontraba moralmente abandonado, pervertido, o en peligro de serlo y fuese menor de doce años el Tribunal de Menores lo entregaría a un establecimiento de educación o a una familia de confianza, donde pudiera ser educado y vigilado, lo mismo se sugería para los menores de 18 años (Art. 396) ${ }^{64}$. En consecuencia, durante la posrevolución la entrega de niñas por instituciones públicas a familias de clase media para convertirlas en sirvientas continuó y se legitimó, aunque sin emplear oficialmente el término «adopción».

59 AGN, CTMI, (1927) caja 1, exp. 1093.

60 AGN, CTMI, (1929) caja 6, exp. 3304.

61 Ceniceros y Garrido (1936), Proyecto de reglamento y lineamientos generales para el funcionamiento de la casa hogar para mujeres, p. 208, 28 de febrero de 1936.

62 El tema de la adopción ha sido estudiado ampliamente por BLuM, A.S. (1998), Children without Parents: Law, Charity and Social Practice, Mexico City, 1867-1940, California, University of California, Tesis de doctorado.

63 Ceniceros y Garrido (1936), p. 251.

64 Ceniceros y Garrido (1936), p. 284., art. 396 y 199. 
Muchas mujeres de clase media solicitaron la liberación de las niñas aprehendidas en las casas correccionales con el ánimo de ocuparlas como sirvientas. Sólo requerían probar ciertos méritos, capacidad económica, solvencia moral y fijar el sueldo mensual que pagarían. En una ciudad en creciente expansión y una clase media que aumentaba paulatinamente la demanda de sirvientas se incrementó y se asoció cada vez más con un símbolo de estatus social. Así, decenas de niñas fueron entregadas arbitrariamente y sin mediar ningún tipo de trámite de adopción a mujeres de clase media ${ }^{65}$.

Esta terapia del trabajo tuvo graves consecuencias pues no todas las casas tenían los índices de moralidad y buenas costumbres que promovían los funcionarios del Tribunal:

\begin{abstract}
¿Quién no ha tenido ocasión de descubrir el misterio con que algunas familias aparentan una vida mejor que la que en realidad pueden permitirse? Son las familias que viven con el peso de una simulación constante, agravada por un exiguo presupuesto que las fuerza a realizar mágicos equilibrios para no quebrar la línea trazada. Y es fatalmente a estas familias a las cuales va a dar la huerfanita que los jueces encargados de la tutela de menores entregan de buena fe. Y es allí donde la criaturita tendrá que vérselas con tres o cuatro solteronas histéricas y con el infaltable niño de la casa, la más perfecta expresión de la tiranía doméstica. Así, la criadita entrará de lleno a batallar con aquella tropa de seres inútiles, en los cuales la única y más desarrollada condición humana es la crueldad con la cual traducen el fracaso de no poder ser lo que sus ambiciones le señalaban ${ }^{66}$.
\end{abstract}

Muchas de las niñas que fueron entregadas como sirvientas eran explotadas, sufrían abusos por parte de sus patrones, sus hijos o los empleados que convivían en los hogares. El espacio doméstico se convertía en un ámbito de poder y dominio del que una niña difícilmente podía escapar y en el cual, como señala Katherine Bliss, los patrones y sirvientes «eran indiferentes a la virginidad de las mujeres pobres que no eran de su familia» ${ }^{67}$. Tanto la señora como el señor de la casa hacían uso de este poder en distintos niveles. Algunos patrones aprovechaban la fragilidad de las niñas, su corta edad, su indefensión y su aislamiento para abusar sexualmente de ellas. Al estar solas ya fuera con el empleador, sus hijos, los demás servidores varones o visitantes,

65 AGN, CTMI, (1927) caja 1, exp. 1127; AGN, CTMI, (1927) caja 1, exp. 1630; AGN, CTMI, (1929) caja 6, exp. 3304.

66 OcAmpo, C. (1927), Las criaditas, El Universal Ilustrado, 3 de febrero, p. 63.

67 BLISS, K.E. (2001), Compromised Positions. Prostitution, Public Health and Gender Politics in Revolutionary Mexico City, Pennsylvania, The Pennsylvania State University Press, p. 39. 
las niñas quedaban en un estado vulnerable ante el peligro. Algunas «señoras de la casa» se hacían cómplices de las prácticas de sus maridos y al mismo tiempo castigaban y se vengaban de las víctimas a través de la imposición de una serie de tareas que, no importando lo extenuantes que pudieran llegar a ser, las niñas criadas debían cumplir.

En pos de proteger moralmente a las niñas, dentro de un discurso a favor de la infancia que permeó las instituciones sociales durante la posrevolución, hubo contradicción y ambivalencia oficial, por un lado se calificó al servicio doméstico como un ámbito inadecuado y desventajoso para las niñas y con este argumento se le negó la solicitud de la libertad a algunas madres que deseaban colocar a sus hijas como sirvientas ${ }^{68}$. Por otro lado se consideró prudente la liberación de las niñas para ubicarlas en casas de «señoritas de buen vivir»o «familias respetables». En ese sentido las niñas sirvientas tuvieron una múltiple marginación, el género, la clase, la edad, lo cual las sometía a la explotación y la violencia de los adultos que las rodeaban.

\section{REFLEXIONES FINALES ¿EFECTIVIDAD? ¿CURACIÓN?}

Durante la posrevolución hubo una convicción de que el tratamiento a través del trabajo corregía, regeneraba, reducía la anormalidad, curaba la enfermedad y, junto a otra serie de terapéuticas basadas en la higiene, la gimnasia y la escolarización, podría normar un nuevo tipo de ciudadano, útil, sano y trabajador. Estas terapéuticas, al estar dirigidas predominantemente a los sectores populares urbanos ${ }^{69}$, buscaron también normar a un nuevo tipo de «populacho» y un nuevo tipo de niño.

El proyecto estatal de convertir a los niños de los sectores populares en pequeños y futuros trabajadores se evidenció no sólo en la capacitación para el trabajo en las instituciones correccionales, sino también dentro de instituciones educativas de la ciudad y en la legislación sobre el trabajo infantil de esos años ${ }^{70}$.

68 AGN, CTMI, (1927) caja 1, exp. 853; AGN, CTMI, (1927) caja 1, exp. 1630.

69 Hay pocos casos de niños de la élite o de la clase media en el Tribunal, quizá no llegaban, se eliminaban sus expedientes o no se elaboraban. Salvador Lima señalaba que «si se conoce poco en público de faltas cometidas por niños de hogares ricos, es porque están poseídos de un miedo terrible al desprestigio social y como un acto natural de defensa propia, prefieren cualquier sacrificio antes que exponerse a la censura de la sociedad». LiMA (1929), p. 6.

70 Temas que desarrollé en mi tesis doctoral: Trabajo infantil en la ciudad de México, 1920-1934. 
En tanto los adultos que se requerían para el fortalecimiento económico nacional debían formarse desde la niñez, era necesario delinear los caminos por los que se deseaba que transitaran las clases populares. La terapéutica para la corrección de la delincuencia infantil formó parte de un proyecto económico estatal para crear trabajadores y hacer de los niños de las clases populares los futuros obreros y someterlos a un aparato de producción ${ }^{71}$. Formó parte también de un proyecto social para desarrollar en ellos «destrezas de clase baja y valores de clase media» ${ }^{72}$, y para reproducir roles de género y la idea de un ciudadano trabajador. En ese sentido, esta fue una política clasista, sexista y claramente determinista en la que el trabajo fue concebido como un agente de rehabilitación y de regeneración de la salud mental y física, pero también como un agente de diferenciación social.

Los discursos médico, psiquiátrico, jurídico, pedagógico y económico, confluyeron en la terapéutica del trabajo para combatir la delincuencia infantil. Aunque, la ley prohibía la contratación de menores de doce años, el Estado mexicano obligó a los niños de los sectores populares a desempeñar labores económicas desde muy corta edad. Al salir de la cárcel, los niños fueron encaminados a talleres o fábricas y al servicio doméstico, con el argumento de que en tanto eran niños pobres, el trabajo les capacitaba para su «vida real», para las nuevas actividades que desempeñarían en libertad y los espacios y roles masculinos/femeninos que ocuparían. Un estado que debía velar por la infancia, que debía protegerla de los abusos y de la explotación laboral, decidió no sólo utilizar mano de obra infantil en los establecimientos educativos y correctivos sino también bajo una disimulada terapéutica, formarla para trabajar precozmente en los talleres, fábricas y hogares de la gran ciudad.

Fecha de recepción: 31 de agosto de 2007.

Fecha de aceptación: 27 de marzo de 2008.

71 Foucault (1984), p. 246.

72 Platt (1998), p. 92. 